\title{
Toxic psychosis with antihistamines reversed by physostigmine
}

\author{
P. J. COWEN \\ B.Sc., M.B. \\ Department of Psychological Medicine, King's College Hospital, \\ Denmark Hill, London SE5 9RS
}

\begin{abstract}
Summary
A case of toxic psychosis due to antihistamine poisoning is described. The reversal of this state by physostigmine supports the contention that it is caused by an anticholinergic syndrome. The management of antihistamine poisoning is discussed.

\section{Introduction}

Toxic psychosis is a recognized complication of antihistamine poisoning (Goodman and Gilman, 1975). It has been suggested that this toxic state might be caused by anticholinergic mechanisms and that treatment with physostigmine could reverse it (Granacher and Baldessarini, 1975). Despite this, physostigmine is not usually recommended in the management of antihistamine poisoning. A case is now reported of antihistamine poisoning which was complicated by marked central symptoms. These symptoms were abolished by physostigmine salicylate.
\end{abstract}

\section{Case report}

A 40-year-old housewife was admitted to the medical ward having taken an unknown number of promethazine tablets. She was deeply unconscious and responded only in a sluggish and inco-ordinated manner to pain. Her pulse was 104 beats/min. Her pupils were dilated and did not react to light. The deep tendon reflexes were present and symmetrical but both plantar responses were extensor. Gastric lavage had been performed in Casualty and $100 \mathrm{mEq}$ of sodium bicarbonate lefi in the stomach. Routine obervations were made and nursing care given.

Six hours after admission her level of consciousness had improved so that she was rousable but increasingly restless and difficult to nurse. Her fluid intake was poor and she was aggressive when approached. This state continued for the next $24 \mathrm{hr}$ during which she received 2 i.m. doses of chlorpromazine $100 \mathrm{mg}$ and 2 i.m. doses of diazepam $10 \mathrm{mg}$ vithout effect. Psychiatric assessment was requested.

Examination showed a restless, agitated woman who was walking unsteadily around the ward pouring water from a jug over patients and furniture. She was confused, disorientated in time and place, and had visual hallucinations.

There was no previous history of psychiatric ill- or ness. A diagnosis of a drug-induced toxic confusional state with features of an anticholinergic syndrome was made. She was given i.m. physostigmine salicylate $0.5 \mathrm{mg}$, and within $15 \mathrm{~min}$ was calm and able to orientate herself spatially and temporallyp There was no evidence of confusion or visua $\vec{\Phi}$ hallucinations. After $2 \mathrm{hr}$ she again became drows $\mathbb{D}$ and confused but remained quiet and did not presen a nursing problem. Three hours later she was give 3 night sedation of one $\mathbf{g}$ oral chlormethiazole ans $\Phi$ slept until the following morning. She was then lucis and orientated with little memory for the confusion episode. Her mental state remained stable and she was subsequently discharged to attend the psychia:tric out-patient clinic.

\section{Discussion}

The central effects of antihistamines constitute their greatest danger in acute poisoning. The presentation may vary from confusion, hallucinations and convulsions to deepening coma and respiratory arrest. Peripheral effects of poisoning include fixed dilated pupils, tachycardia, flushed skin and pyrexia (Goodman and Gilman, 1975).

In addition to $\mathrm{H}_{\mathbf{1}}$-receptor blocking properties, antihistamines also possess peripheral and central anticholinergic effects (Goodman and Gilman, 1975). It is becoming increasingly recognized that drugs whose properties include anticholinergic activity may, in acute poisoning, produce a picture typical of peripheral and central anticholinergic toxicity. Such drugs include the tricyclic antidepressants and phenothiazines as well as more obvious examples such as belladonna alkaloids and anti-Parkinson agents (Granacher and Baldessarini, 1975).

Toxic anticholinergic effects may be reversed by treatment with a suitable anticholinesterase. Physostigmine is most commonly used because in contrast 
to neostigmine it passes the blood-brain barrier and reverses both central and peripheral anticholinergic blockade (Duvoisin and Katz, 1968). The value of physostigmine in atropine poisoning is well known, and more recent reports have described its role in the treatment of tricyclic antidepressant (Janson, Watt and Hermos, 1977) and phenothiazine poisoning (Wang and Marlowe, 1977). It appears that antihistamines, too, may produce an anticholinergic syndrome. Indeed, most if not all of the clinical features of antihistamine poisoning are attributable to anticholinergic toxicity. The reversal by physostigmine of the delirium described in the case report supports this contention. In addition, physostigmine has been shown to reverse central excitement and depression following antihistamine premedication (Lee, Turndorf and Poppers, 1975).

Antihistamine poisoning in adults is not usually a life-threatening event, and simple supportive measures are adequate (Goodman and Gilman, 1975). In children and more severely poisoned adults central complications are frequent, and it is here that physostigmine may play a useful role. Features of the anticholinergic syndrome such as confusion, coma and convulsions may be expected to respond (Rumack, 1973) and, in addition, peripheral anticholinergic blockade will be reversed. Because of the short half-life of physostigmine, demonstrated by the return of symptoms in the case report, re- peated doses may be needed. Physostigmine should be used with caution in patients who have an underlying condition such as heart block or asthma which would contra-indicate excessive cholinergic stimulation (Granacher and Baldessarini, 1975). In these patients, central excitement is best controlled with sedatives which lack anticholinergic effects, for example chlormethiazole or diazepam. Chlorpromazine does possess anticholinergic activity and should be avoided.

\section{References}

Duvorsin, R.C. \& KATZ, R. (1968) Reversal of central anticholinergic syndrome in man by physostigmine. Journal of the American Medical Association, 206, 1963.

Goodman, L.S. \& Gilman, A. (1975) The Pharmacological Basis of Therapeutics. 5th edn, p. 603. MacMillan, New York.

Granacher, R.P. \& Baldessarini, R.J. (1975) Physostigmine: Its use in acute anticholinergic syndrome with antidepressant and antiparkinson drugs. Archives of General Psychiatry, 32, 375.

Janson, P.A., Watt, J.B. \& Hermos, J.A. (1977) Doxepin overdose: Success with physostigmine and failure with neostigmine in reversing toxicity. Journal of the American Medical Association, 237, 2632.

Lee, J.H., Turndorf, H. \& Poppers, P.J. (1975) Physostigmine reversal of antihistamine-induced excitement and depression. Anesthesiology, 43, 683.

RUMACK, B.H. (1973) Anticholinergic poisoning: Treatment with physostigmine. Pediatrics, 52, 449.

WANG, S.F. \& MaRLOWE, C.L. (1977) Treatment of phenothiazine overdose with physostigmine. Pediatrics, 59, 301. 